This item was submitted to Loughborough's Research Repository by the author.

Items in Figshare are protected by copyright, with all rights reserved, unless otherwise indicated.

\title{
Effective triaging in general practice receptions: a conversation analytic study
}

PLEASE CITE THE PUBLISHED VERSION

https://www.bloomsbury.com/uk/applying-linguistics-in-illness-and-healthcare-contexts-9781350057661/

PUBLISHER

Bloomsbury Academic

VERSION

AM (Accepted Manuscript)

\section{PUBLISHER STATEMENT}

This book chapter was published in the book Demjen, Z. (ed.). Applying linguistics in illness and healthcare contexts. The publisher's website is at https://www.bloomsbury.com/uk/applying-linguistics-in-illness-andhealthcare-contexts-9781350057661/

\section{LICENCE}

CC BY-NC-ND 4.0

\section{REPOSITORY RECORD}

Sikveland, Rein O., Elizabeth Stokoe, and Z. Demjen. 2020. "Effective Triaging in General Practice Receptions: A Conversation Analytic Study”. Loughborough University. https://hdl.handle.net/2134/35240. 


\section{Effective triaging in general practice receptions: a conversation analytic study}

\section{ABSTRACT}

When patients call to make appointments at the doctors, the relative urgency of their healthcare needs is something that 'triaging' systems are designed to establish. This chapter investigates how receptionist-led triage unfolds in patients' calls to general practice surgeries. We collected 2780 audio-recorded telephone calls from three UK surgeries, transcribed them and used conversation analysis to study the real-time interaction between receptionists and patients. We focused on receptionists' initial responses to patients' requests to make a doctor's appointment, and how receptionists established whether patients' medical needs require (i) a same-day appointment with a doctor, (ii) a call-back from a doctor or nurse, or (iii), if not urgent, an appointment on a future date. We show how variation in the way receptionists initiated the triaging, i.e., how they sought to establish whether or not the request was urgent enough for a same-day appointment, was consequential for the smooth progress of the interaction. First, when receptionists initiated triaging with a polar interrogative asking patients to (dis)confirm their problem as 'routine' ('is it just a routine appointment?'), or when contrasting 'routine' and 'urgent' ('is it urgent or routine?'), patients were reluctant to confirm either way. Second, triaging progressed more smoothly when receptionists asked questions that solicited accounts. Interrogatives that were effective in soliciting an account from the patient included both polar interrogatives ('is it something (urgent) for today?'), and wh- interrogatives ('may I ask what the problem is?'), but the latter was more problematic for patients who wish to withhold their reason for seeing the doctor. Third, when patients, in their initial inquiries, did not describe their problem as urgent, they readily accepted a future appointment - suggesting that receptionists need not ask about urgency at all, in the first instance. Our findings have implications for GP receptionist training and wider practice policies.

\section{Introduction}

In UK general practices (GPs), there is a mismatch between patient demand for and availability of same-day appointments. This mismatch has implications for receptionist, nurse and doctor workload (Gallagher, Huddart and Henderson, 1998; Campbell et al., 2014); for increased burden on accident and emergency (A\&E) departments (Bunn, Byrne and Kendall, 2004), and for patient satisfaction (Liston, 2013). 'Triaging' - the process of assessing patients' healthcare problems in order to refer them to appropriate services or appointments is used widely to manage increasing demand for care (O’Meara, Porter and Greaves, 2007). In general practice surgeries, telephone receptionists assess whether patients' need a sameday doctor's appointment, a call-back from a doctor or nurse, or a future appointment. But while the effectiveness of triaging (including by telephone) has been studied extensively ( Munro et al., 2000; O’Meara, Porter and Greaves, 2007; e.g., Campbell et al., 2014), the role and effectiveness of the GP receptionists in initiating triaging has received comparatively little attention (Gallagher et al., 2001; Hall et al., 2011). The starting point in our research is 
that front-line receptionists may engage in both effective and less effective practices in the way they initiate triaging, and to understand this difference we need to explore these interactions in terms of how language is used. In this chapter, we explore receptionist-led triaging as it unfolds when patients phone to book a doctor's appointment. We are particularly interested in how receptionists may conduct the triaging more, or less, effectively through the linguistic practices they use.

Using conversation analysis (CA), a method which exposes participants' own tacit understanding of each preceding turn of talk (Drew et al. 2001), we identify linguistic and interactional patterns across a large dataset of GP receptionist telephone calls. To introduce our approach, we present the following example, where a patient (P) is phoning the GP reception to book an appointment to see a doctor:

Extract 1a: GP2 428

1

2

3

4

5

6

7

8

9
( ( ring ) )

R: Good morning reception.=Melanie speaking,

$(0.4)$

P: $\quad$ Good $\uparrow$ morning. $=\left(I^{\prime} d\right)$ like <to $>$ make an appointment to see a doctor please.

$(1.1)$

R: Is it just a routine appointment,

$(0.7)$

P: Uh: : $(0.8)$ \how do you mean.

Following the patient's (P) request to make an appointment (lines 4-5), the receptionist (R) initiates triaging with yes-no interrogative question, 'Is it just a routine appointment,' (line 7), requiring confirmation. But in response, $\mathrm{P}$ shows that he does not understand how to respond ('how do you mean.', line 9). Thus the receptionist's request for confirmation creates a break in the progressivity of this encounter and in the triaging; the receptionist must now instead explain further.

The questions asked and explored in this study are based on similar observations, across a large dataset. For example: is the patient's understanding of 'routine' a general problem in these calls? If so, what alternatives do receptionists have to initiate the triaging, while avoiding such trouble as observed in Extract 1a? Are there more effective ways of asking about patient need? Before giving more details on the method and data studied (Section 3), we contextualize triaging in other research on patient-receptionist encounters (Section 2). In Sections 4.1-3, we present our analysis, and in Section 5 we address the implications of our findings for healthcare practice, and training, ahead of some concluding remarks (Section 6).

\section{Context: General practice receptions, triaging, and the gatekeeping of patient care}

When patients want to be seen by their GP doctor, they are most likely to contact their GP service by telephone: about $86 \%$ of patients report they use the telephone to make a doctor's appointment (UK GP Patient Survey of July 2017; https://gp-patient.co.uk). GP receptionists 
therefore act as a 'gatekeeper' between patient needs and the availability of healthcare practitioners. Given the importance of receptionists' role at the beginning of the patient journey, there is comparatively little research on patient-receptionist encounters (Hewitt, McCloughan and McKinstry, 2009; Neuwelt, Kearns and Cairns, 2016). Existing studies are often reflective of, or responding to, the stereotype of receptionists as 'dragons' or as 'gatekeepers' that is prominent in media discourse. Some academic research supports this notion by highlighting receptionists' strong intermediary role in their everyday dealing with patients, and how patients may perceive them as insensitive or routine-driven (Arber and Sawyer, 1985; Paddison et al., 2013). Other studies draw a more nuanced picture, suggesting that particular complexities and constraints in the receptionists' job affect their ability to facilitate patient access (Swinglehurst et al., 2011; Hammond et al., 2013; Neuwelt, Kearns and Cairns, 2016). For example, while patients see their concern as important enough to see a doctor, the receptionists are constrained by limited resources such as lacking availability of same-day appointments to see a doctor or nurse. Receptionists report that these are challenging aspects of their work (Gallagher et al., 2001; Hesselgreaves, Lough and Power, 2009); however, the empirical question remains how receptionists best meet these challenges when dealing with patients.

Triaging is implemented to manage the workload generally within primary care, and GP receptionists, as the patients' first point of contact, make the first triaging decisions for their general practice. Triaging is not a straightforward task, neither in terms of risk. For example, there are a variety of medical factors potentially relevant to whether a patient ought to be seen on the same day, and receptionists might therefore engage in clinical decisions they are not trained to make (Neuwelt, Kearns and Cairns, 2016). As the triaging decisions have the potential to affect outcomes for patients (Hall et al., 2011), there are health risks involved for the patients as well as legal risks for the general practitioners (Patterson, Del Mar and Najman, 2000; Patterson et al., 2005).

Previous studies have primarily assessed the effectiveness of triaging as a system, in terms of number and duration of doctor's appointments, costs, hospital attendance, risk, and patient/doctor satisfaction (Richards et al., 2004; Campbell et al., 2014; Gillam, 2014). However, quantitative features such as duration of telephone consultations compared to faceto-face encounters are not themselves evidence of the effectiveness of patient care. Other studies have therefore assessed triaging quality, primarily based on doctor-patient encounters. Hewitt et al. (2010) compared face-to-face and telephone patient-doctor consultations, and, while they found few underlying communicative differences between the two, patients addressed a wider range of problems in face-to-face rather than telephone consultations. When on the telephone, doctors were less likely to elicit additional concerns and asked fewer questions when patients presented problems associated with treatment or diagnosis. Instead of addressing complex issues on the telephone, doctors arranged a face-to-face consultation. Murdoch et al. (2014) compared doctors' and nurses' triage telephone consultations with patients. They found that nurses deployed a series of contracted, declaratively formed, requests for confirmation to gather information around a reported symptom (such as 'and 
she's weeing okay'), whereas doctors took a more unknowing stance with yes/no questions (e.g., 'has she vomited at all'), thereby allowing for more elaboration from the patient.

Murdoch et al.'s (2014) study showed the differential consequences language - in their case question design - can have on the trajectory of the encounter. How clinicians communicate with patients in telephone triage is therefore central to decisions about triage delivery within primary care. But while Murdoch et al. studied the already-triaged consultations, the delivery of triaging starts much earlier, when receptionists assess patient need for a same-day appointment. This is the focus of our study.

Few studies address how receptionists initiate the triaging process, and none provide evidence of the impact of language choices on outcomes. Gallagher et al. (2001), in an interview-based observational study of receptionist triaging, highlighted the complex and negotiated aspects of appointment bookings, and formulated the problems from the patients' point of view: 'some patients do not understand or accept the criteria used for allocating appointments and dislike giving clinical information’ (p. 284); and from a GP practice point of view: 'a more patient-orientated approach to appointment making could foster a more equal partnership between patient and receptionist.' (p. 284). Gallagher et al. (2001) propose that practices provide explicit instructions to patients about how appointments are allocated, and to receptionists' strategies for communicating these. But, while they suggest that a pragmatic and flexible approach is needed to effectively deal with patients' requests, they do not offer specific recommendations for practice.

Other studies also suggest the differential and context-sensitive nature of receptionist-led triaging (O’Meara et al., 2007; Hall et al., 2011), arguing that triaging practices that work in general practice might require adaption in other types of primary care practice (e.g., emergency care). Hall et al. (2011) proposed a triaging protocol for non-clinical (receptionist) staff, adaptable to different practices and contexts, and evaluated in terms of the safety and quality of the decision making, amongst other things. The outcome measures they proposed would be scored by an expert panel, and to be based on receptionists' self-reported behaviour in response to a series of hypothetical patient scenarios. The problem with this approach, as with other quality-of-care studies based on surveys or self-reports (e.g., Bensing et al., 2013; Paddison et al., 2013), is that they fail to explain how and when problems occur in encounters, and therefore we do not know what needs improving or how to improve (see also Sikveland, Stokoe and Symonds, 2016). Hall et al. (2011) themselves acknowledge some of the challenges with their approach, in terms of the interpretation required, both on the part of the receptionists and the panel, and problems with the 'real-world' relevance.

We show that only by studying the specific unfolding of how receptionists deal with their everyday challenges, can we respond to questions about context-sensitivity, differential treatment in different services, and, in our case, the effectiveness of receptionist-led triaging. For example, while information from the patient about their conditions helps receptionists to direct them to the right kind of appointment (Gallagher et al., 2001), we know little about how such a decision is best facilitated, or not, by the receptionist. How do receptionists best gather information based on which they can conduct the triaging? By initiating the triaging 
effectively, receptionists might also avoid both over-triaging (i.e., patients who need urgent care do not get it), and under-triaging (i.e., too many patients get a same-day appointment where it is not needed) (O’Meara, Porter and Greaves, 2007).

In Section 3 we explain in more detail how we explore this problem, using conversation analysis (CA).

\section{Introduction to Research Design and Method}

The dataset for this study comprised 2780 recorded incoming telephone calls from patients to three General Practice surgeries in the UK. The recordings were anonymized digitally, in line with ethical practice when using recorded conversational data (Speer and Stokoe, 2014). Consent was granted by the NHS for our evaluation of the data. 1,555 of the calls, approximately 500 calls from each of the three surgeries, were transcribed verbatim, and formed the basis for the current analysis. Two out of the three GP surgeries implemented triaging by default. Focussing on these two surgeries, we collected, analysed and compared the different forms of triage-initiation, that is, sequences of talk starting with a patient's initial request to book an appointment, followed by the receptionist addressing the urgency and/or nature of the patient's request. All of the transcripts containing target sequences were transcribed using the Jefferson (Jefferson, 2004) system for conversation analysis, which encodes prosodic, pacing and other phonetic information about the way talk is delivered (see transcription conventions in the appendix).

The data were analysed using conversation analysis (CA. In CA, the primary focus is on social actions and how these are shaped based on a set of linguistic and interactional structures. CA work shows how speakers and listeners regulate and coordinate participation in talk, and that there are particular norms for organising talk in turns and sequences of turns (Schegloff, 2007). Based on these norms speakers and listeners may identify interactional 'trouble' through a delay in response, for example, and act accordingly. A conversation analyst starts by repeatedly viewing or listening to recorded data, and transcribing the data with information about verbal and non-verbal activities and the way those activities are designed and structured in turns and sequences of turns. . It proceeds to analyse systematically how different designs and structures lead to different outcomes within the interaction. In CA such evidence is based on the principle of 'next-turn proof procedure', which exposes participants' tacit understanding of each preceding turn of talk and of the action it comprised, rather than relying on analysts' a priori interpretations of what is happening (Drew, Chatwin and Collins, 2001).

We focused on the design of actions used in triaging. Relevant actions here include requesting (i.e., a doctor's appointment), which form the first part of a sequence (i.e., an 'adjacency pair' Schegloff, 2007), for which granting or non-granting are relevant outcomes in the next turn. Using CA, we pay special attention to how this interactional sequence unfolds; that is, the consequences of the request and the request response for what happens next in the encounter. In our analysis we focused on 1) how patients created a circumstance 
where it was necessary (or not) to address their need for a same-day appointment in their request (e.g., 'I need an appointment to see a doctor today'); 2) how receptionists solicit more information for triaging purposes in their initial response (e.g., 'is it a routine appointment?', 'is it urgent?', 'what is it for?'); and 3) how effective different methods for informationsoliciting are for conducting the triaging. Our assessment of 'effectiveness' is based on features endogenous to the interaction, showing whether the patient understands the question and/or treats it as congruent with their inquiry.

\section{Negotiating urgency at the GP reception}

Receptionists frequently initiated triaging by asking patients to confirm that their request was either 'urgent' or 'routine'. But neither category was treated by the patient as relevant to their request. Patients subsequently accounted for their request in more detail, providing information relevant to triaging; however, the manner and ease with which patients did so depended on the linguistic format used by receptionists to initiate the triaging. In Section 4.1, on 'ineffective triaging', we show how patients rejected 'routine' as fitting to their inquiry, on the basis that their needs were more than trivial. We propose that triaging is best conducted without reference to 'routine'. However, patients were also reluctant to confirm their needs were 'urgent'. In Section 4.2, on 'effective triaging', we show how some formats were more effective in soliciting an account from patients about why their needs were urgent enough for a same-day appointment. Overall, triaging ran more efficiently when receptionists asked polar interrogatives such as 'is it something (urgent) for today (you're requiring)', rather than asking the patient to choose between 'urgent' and 'routine' (e.g. 'is it urgent or routine?'). Wh-interrogatives such as 'may I ask what the problem is?' also solicited accounts, however, such triaging forms became a problem for patients who wanted to withhold their reason for seeing a doctor. Finally, in Section 4.3, on 'flexible triaging', we show how patients themselves indicated urgency in their first turn, with implications for whether and how it is relevant for receptionists to initiate triaging. In cases where patients did not indicate urgency in their first turn, they were usually satisfied to receive an offer of a future appointment.

\subsection{Ineffective triaging: Resisting 'routine' appointments}

In Extract 1b, patient (P) requests an appointment to see a doctor (see Appendix for an introduction to the transcription method).

Extract 1b: GP2 428

1
( $(r$ ing $)$ )

R: Good morning reception.=Melanie speaking, $(0.4)$

P: Good $\uparrow$ morning. $=\left(I^{\prime} d\right)$ like <to> make an appointment to see a doctor please.

(1.1)

R: Is it just a routine appointment, $(0.7)$

P: Uh: : $(0.8)$ ฟhow do you mean.

$(0.8)$

R: Well I've either got iurgent for today_ Bu:t::- uh: I'll have to get the doctor to give you a ring back with telephone 


\author{
advice=0r we are booking Monday. \\ (1.4) \\ P: Uh that- (will) be fine for Monday,=That'll be no problem,
}

Following the receptionist's (R's) greeting, P returns the greeting ('Good morning') and formulates his request 'I'd like <to $>$ make an appointment to see a doctor please.' (lines 4-5). As in many other call openings, $\mathrm{R}$ does not explicitly grant or reject the patient's request in line 7, but instead initiates triaging with an insert sequence to specify type of appointment: 'Is it just a routine appointment,'. Triaging is also evident in lines 11-13 as R explains the process of deciding whether to offer $\mathrm{P}$ a same-day appointment or a call-back from a doctor.

From a general service perspective, 'is it routine’ in this sequential location may be understood as a way of building an appropriate service response based on components incrementally specified over an extended sequence of talk (Lee, 2009). In other words, 'is it routine', if responded to with a confirmation, narrows down the relevant service offers, and serves to make the patient's inquiry appropriate to the institution to which it is directed. But while this order of events might make sense from an institutional perspective, it is not straightforward for the patient, as evidenced in his next turn (line 9): 'how do you mean.' . Unlike 'pardon', 'huh' and other words that initiate repair (Drew, 1997), P here shows he has heard what R said, but that he does not follow its relevance or presuppositions in terms of his own inquiry (Sidnell, 2016). Note also a common design feature of R's request; it constrains patients either to confirm R's presupposition that P's needs are minimal ('just') and ordinary ('routine) otherwise the patients have to do extra work to formulate a disagreeing (or 'dispreferred’) response (Schegloff, 2007).

In most cases where triaging is initiated with reference to 'routine', patients do display some understanding of its implications; however, patients generally resist it as a category fitting to their request. Extract 2 is typical.

Extract 2: GP2 216

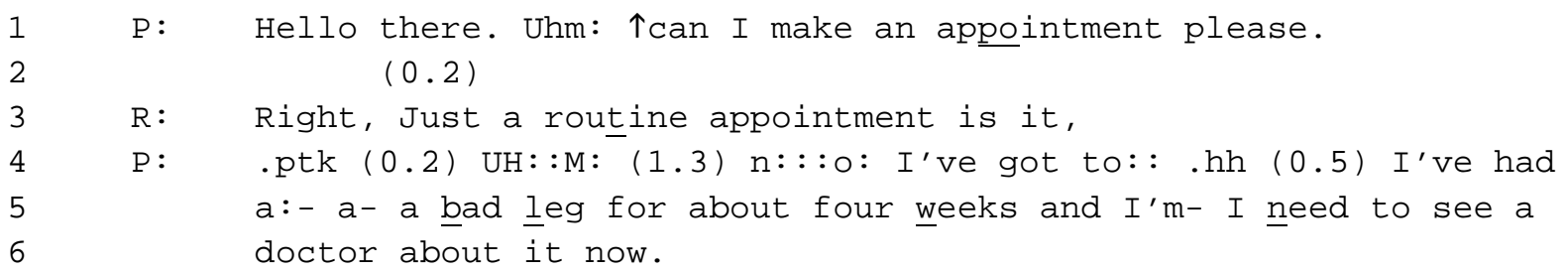

Following P's enquiry to make an appointment (line 1), R acknowledges the enquiry ('Right,', line 3) and then, as in Extract 1b, initiates triaging with 'Just a routine appointment is it,'. R's triage-query takes the form of a declarative interrogative and a 'confirmation request' (Heritage and Raymond, 2005; Murdoch et al., 2014), which does not formulate any alternatives to 'routine', but presents 'routine' appointment as the relevant category for $\mathrm{P}$ to accept or not accept. R thereby suggests, possibly based on P's initial inquiry (line 1), that there is so far not sufficient evidence of a need for a same-day appointment. We will return to 
matters of spotting urgency in the patients' first turn in Section 4.3; for now we focus on the patient's displayed resistance to a 'routine' appointment.

From the very outset of P's response it is clear that there is not going to be a straightforward confirmation ('yes') to categorise her inquiry as 'routine': the turn starts with a delay followed by a prolonged 'UH::M:', followed by another pause and a prolonged, hesitant 'n:::o:'. P then proceeds with an account for having said 'no' (Robinson and Bolden, 2010). P accounts for her 'non-routine' needs by providing details of the nature and duration of her problem 'I've had a bad leg of about four weeks' (lines 4-5), followed by an explicit response to the implications of 'routine' with 'I've got to::' and 'I need to see a doctor about it now' (lines 4-6). In this way, P must work to demonstrate that her enquiry is more than 'routine'. As in Extract 1b, R's use of 'just' (line 3) already frames 'routine' as something 'less important', or 'ordinary', and P's account builds support against such a description of her needs.

It is important to note that, while the patient describes her needs as more than 'routine', she does not categorise it as 'urgent', which is the alternative category used by receptionists in our data. Similarly, the patient in Extract 1b accepted the receptionist's offer of the next available appointment (instead of requesting a same-day call-back), without themselves categorising their needs as 'routine'. In other words, appointment-making is hindered rather than facilitated by the receptionist's presumption of 'routine'.

In Extract 3, note again how the patient orients to her (in this case, son's) needs as 'more than' trivial or ordinary.

\section{Extract 3: GP3 126}

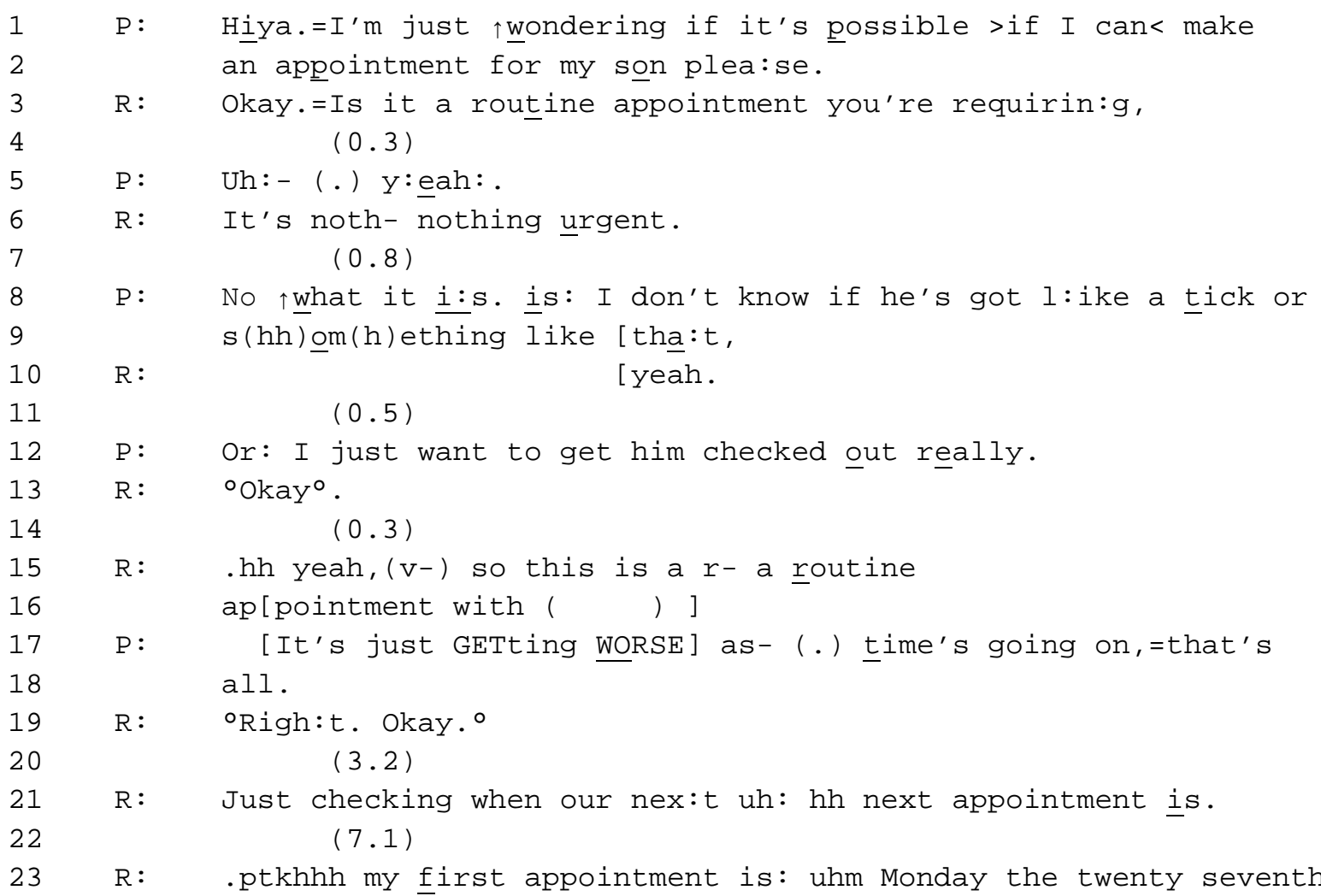




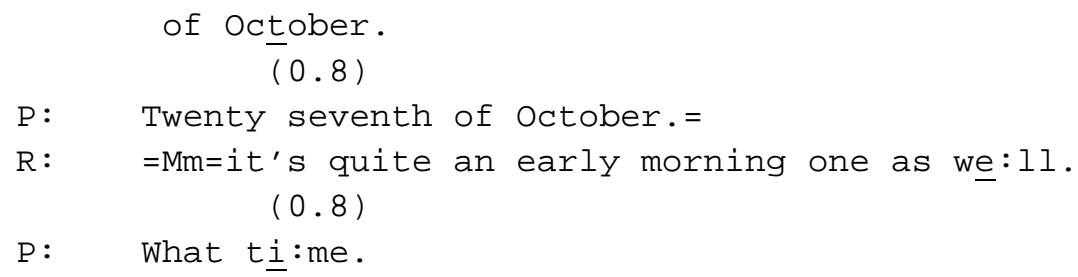

$\mathrm{P}$ is phoning on behalf of her son to book an appointment (lines 1-2), and $\mathrm{R}$ initiates triaging in line 3: 'Is it a routine appointment you're requirin:g,'. As in Extract 2, P's following turninitiation indicates that a confirmation is not straightforward: 'Uh:-' (line 5) suggests that the question is inapposite, and possibly that $\mathrm{P}$ is not clear how to respond. After a micro-pause, $\mathrm{P}$ produces a 'y:eah:.', but, as with the patient's 'no' in Extract 2 (line 4), it is produced hesitantly by being phonetically prolonged with relatively flat falling pitch contour. $\mathrm{R}$ picks up on P's displayed uncertainty, by naming the alternative category to 'routine', as 'urgent' (line 6). R's 'it’s noth- nothing urgent.' (line 6) is geared towards a 'no' confirmation, thereby offering $\mathrm{P}$ with information which might help her. Based on two contrastive options, $\mathrm{R}$ seeks to disambiguate 'routine' as the most appropriate definition of her needs. P responds with a delayed 'no' in line 8 , followed by an account of what the problem is. In this way $\mathrm{P}$ treats both 'routine' and 'urgent' as not quite fitted with her inquiry and with the account she leaves her concerns open to categorisation by the receptionist.

P expresses uncertainty of what the problem is, explicitly with 'I don't know', and by indicating imprecise knowledge in 'he’s got l:ike a tick or s(hh)om(h)ething like tha.t,' (lines 8-9). Following a 0.5 s gap (line 11), P makes explicit her decision to seek GP consultation: 'I just want to get him checked out really.' (line 12). R does not treat this as worthy of a sameday appointment and goes on to offer a 'routine' appointment in lines 15-16. In overlap, and prior to a complete offer from R, $\mathrm{P}$ proceeds with more details on how her son's condition has become increasingly worse. This constructs her concern as a real one that has been evolving for some time, rather than as premature or tentative. Through the placement and design of her response in line 17, $\mathrm{P}$ treats $\mathrm{R}$ 's reference to 'routine' as problematic: $\mathrm{P}$ initiates her turn with increased loudness and pitch, associated with a competition to speak (French and Local, 1983; Sikveland and Zeitlyn, 2017), in this case with the receptionist. R acknowledges P's reiterated concern in line 19 ('Righ:t. Okay.'), followed by an offer to check the next available appointment.

P accepts the next available appointment in line 30, after $\mathrm{R}$ asserts that morning appointments are available (line 17). Again (like in Extract 1), while R implicitly treats the appointment as 'routine', she is not met with resistance when moving towards offering next available appointment without categorising it as 'routine', suggesting that it is the categorisation of their needs as 'routine' that leads to resistance, not necessarily offering a future-date appointment. Instead of immediately offering the next available appointment, the receptionist first has to deal with substantial resistance from $P$. 
Let us consider in more detail the challenges patients face when given a choice between 'routine' and 'urgent'. Extract 4 shows that even when it is straightforward for patients to disconfirm 'urgent', they still resist confirming 'routine' as relevant.

Extract 4: GP3 292

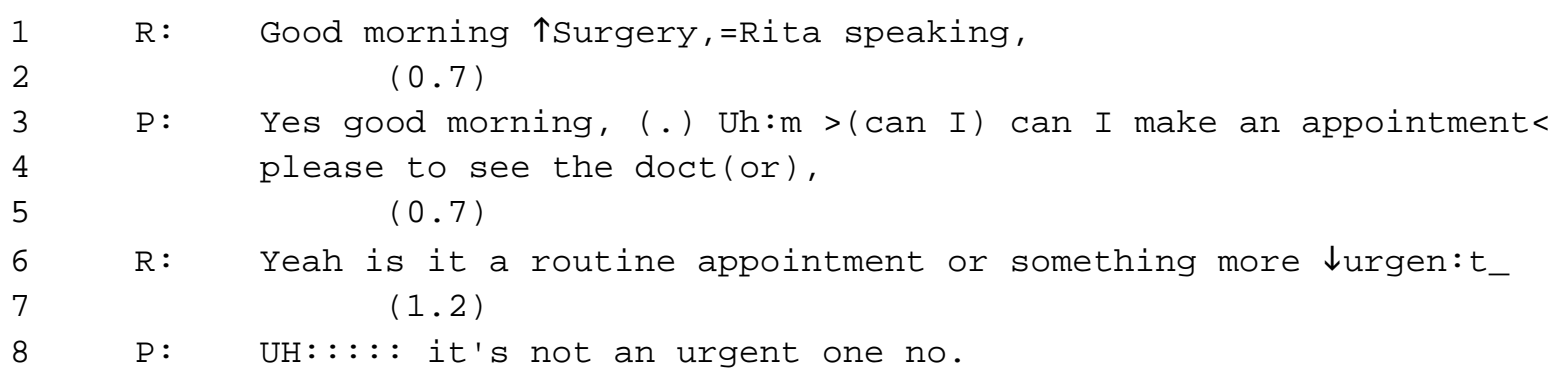

R sets up a contrast between 'routine' and 'urgent', followed by a slot (line 7) for P to select an option. In this case, $\mathrm{R}$ formulates 'urgent' as 'more' compared to 'routine', thereby hearable as treating 'routine' as something 'less'. Following a long gap (line 7) and a markedly prolonged 'UH:::::::' (line 8), P implicitly accepts the first option, 'routine’, although not explicitly so; again, $\mathrm{P}$ avoids categorising his own needs as 'routine'.

In Extract 5, the order of the options 'routine' and 'urgent' are reversed compared to Extract 4.

Extract 5: GP3 138

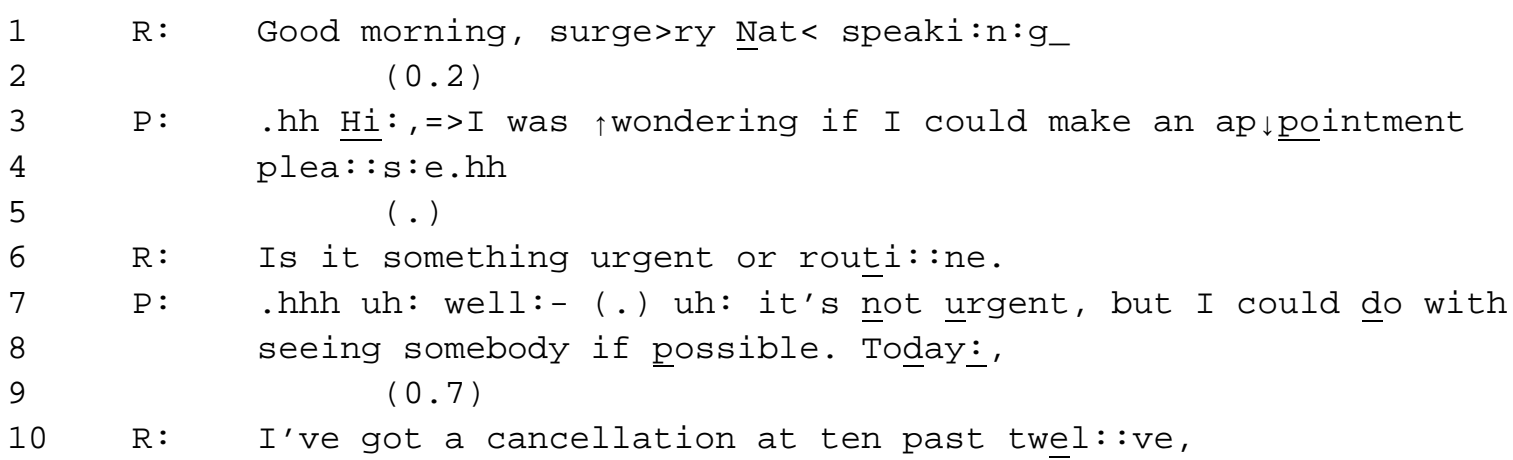

R formulates the triaging as 'Is it something urgent or routi::ne.' (line 6), requesting that $P$ choose between the two categories. R's query is followed by P's delayed and hesitant response in lines 7-8. In her response $P$ resists the terms of receptionist's question, by avoiding both a 'yes' and a 'no', and favouring her own view (with 'well:'; Heritage, 2015). That is, although P does not regard her inquiry as urgent ('it's not urgent, but...', line 7), she favours being seen sooner rather than later, and in this way treats her inquiry as non-'routine', i.e. as legitimate and non-trivial. Without addressing the level of urgency (or P's condition) any further, R offers a same-day appointment in line 10, seemingly treating P's inquiry (like $P$ herself) as urgent. 
Extract 5 highlights some of the complexities around asking for urgent appointments: $\mathrm{P}$ resists non-urgency, and might also resist accounting for her appointment. At least in this case $\mathrm{R}$ has established that $\mathrm{P}$ considers her own enquiry as urgent enough for a same-day appointment. We examine one final extract in this section, in which the patient hears and understands, and rejects, the notion of 'routine' appointment.

Extract 6: GP3 78

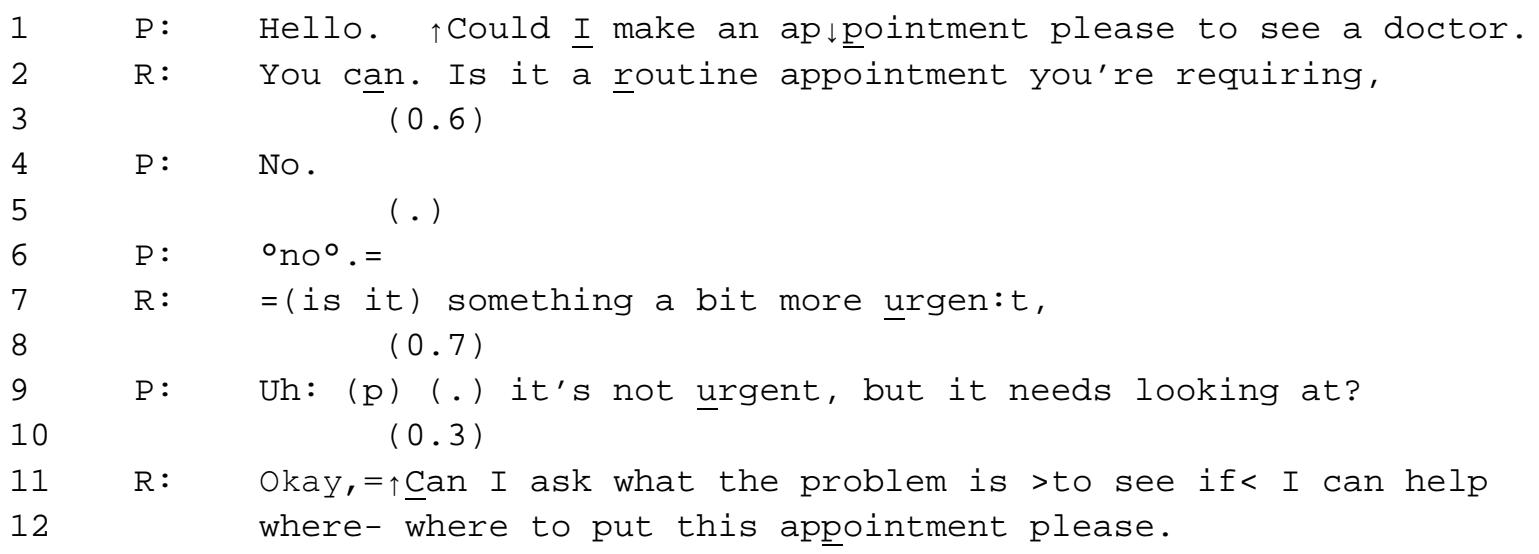

P's appointment request is met with an explicit granting, 'You cann.' (line 2), leading to further specification of R's request, this time with a polar interrogative 'Is it a routine appointment you're requiring,' (line 2). Polar interrogatives typically make an account relevant if the answer is 'no' (Bolden and Robinson, 2010), however, asking just 'is it routine' leads to resistance and no account. $\mathrm{P}$ re-completes the sequence with a second 'no' in line 6, as a confirmation that no further action is taken on his part to expand on the response (Curl, Local and Walker, 2006; Sikveland, 2012). At this point, immediately following P's second 'no' in line 7, R pursues a response with another polar interrogative, requesting $\mathrm{P}$ to confirm whether it's 'urgent'. Again, P resists categorising his needs as 'urgent', as well as 'routine', but stresses the point (and reason for calling) that 'it needs looking at?' (line 9). Now, as $\mathrm{P}$ has resisted giving any information or claim of urgency, R goes on to ask more explicitly what P's needs are (lines 11-12).

In sum, we have shown that, when receptions initiate triaging, they often ask about (or presume) the likely routine nature of patient requests. Receptionists initiate triaging either by a) formulating polar and declarative interrogatives containing the category 'routine', which prefer a confirmation, or b) using alternative interrogatives requiring patients to opt for either 'routine' or 'urgent'. While receptionists and patients may be familiar with the categories 'urgent' and 'routine', patients are reluctant to categorise their needs with either term. We may speculate whether 'routine' is not a description patients themselves would use to account for their calling the doctor (i.e., their reason for calling is more important than 'routine'), and whether 'urgent' lies at the other extreme - again not quite fitting with the patient's reason for calling the doctor (as opposed to phoning 999). In any case, asking patients to confirm 'urgent' or 'routine' seems ineffective. So how can triaging be done more effectively? In 
Section 4.2 we see how a reference to 'urgent' can be productive in soliciting an account, which informs the triaging rather than hindering it.

\subsection{Effective triaging: soliciting accounts when patients request a same-day appointment}

In this section, we report alternative ways in which receptionists initiated triaging without the 'routine/urgent' distinction, and instead solicited an account for patients' needs for a sameday appointment. The first, and most direct way, receptionists did so was by formulating a wh-interrogative, e.g. 'what is it for?'. In Extract $7 \mathrm{P}$ is phoning to book an appointment for her child, and R initiates the triaging with 'May I ask what the problem is today plea:se,' (line 3).

Extract 7: GP3 240, $0: 07-0: 19$

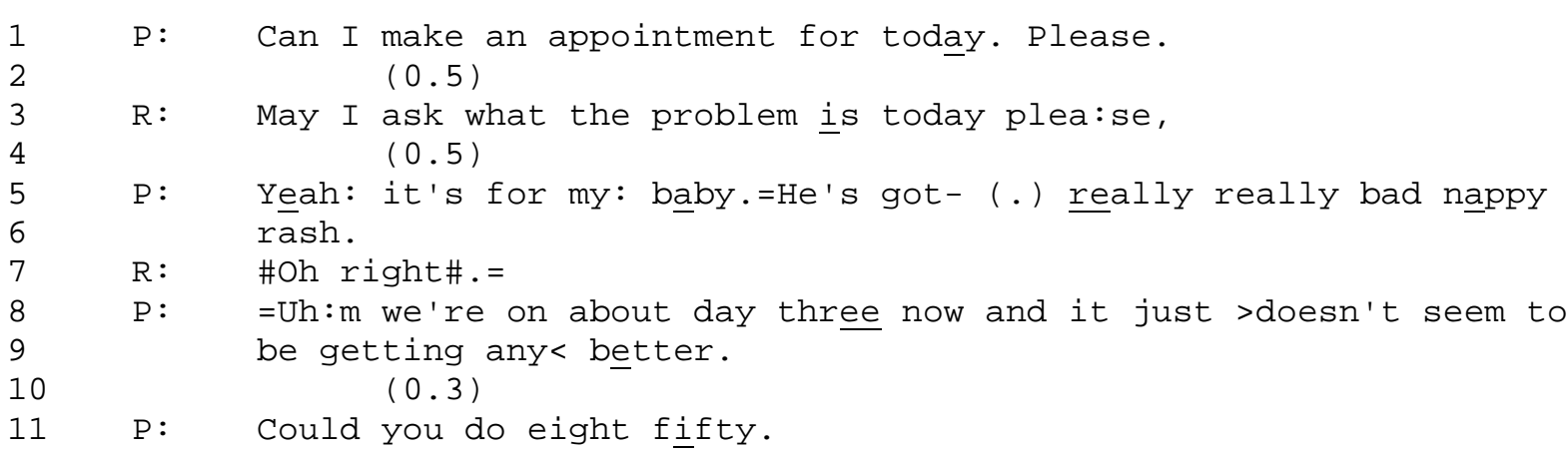

P responds to R's wh-interrogative, first by confirming R's 'may I’ ('yeah:', line 5), then providing 'what' her reason is for making an appointment (lines 5-6), which she further supports in lines 8-9 by highlighting the continued presence of her child's condition. Based on this example, we may argue that wh-interrogatives are an effective way of soliciting an account.

In Extract 8, however, the nature of the wh-interrogative becomes a problem for the patient. $\mathrm{P}$ is phoning to book an appointment on behalf of her husband.

Extract 8: GP3 89, $\odot: \odot 3-\odot: 15$

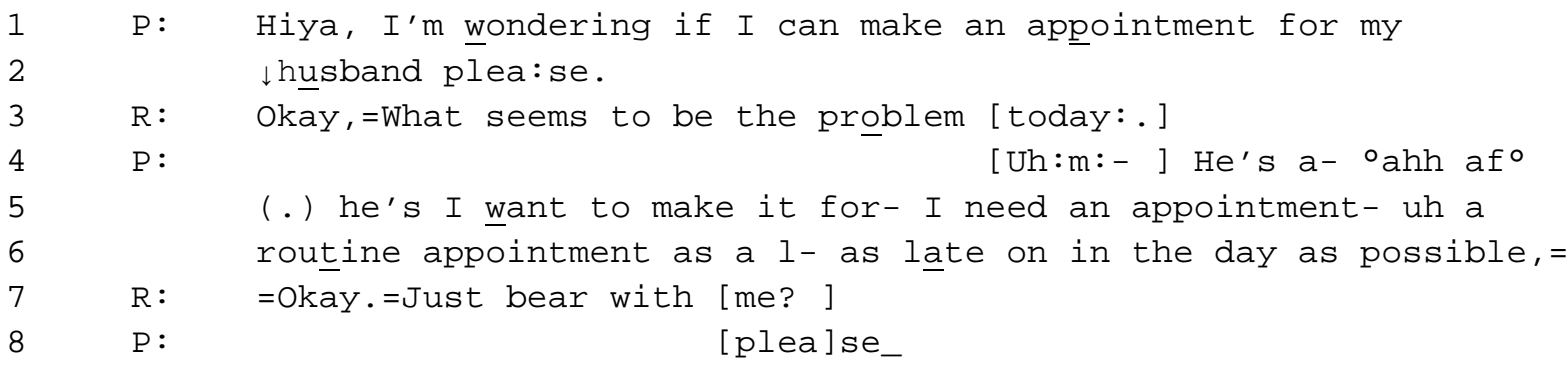


P delays her response in line 4 ('Uh:m:-'), followed by two aborted phrasal initiations: 'He's a-' (line 4), 'he's' (line 5), following which P redirects the trajectory of her turn towards the need for an appointment: 'I want to make it for- I need an appointment-' (line 5). The continued stops and restarts suggest trouble in producing an answer not fitted to the question. As $\mathrm{P}$ proceeds, she ends up specifying her request to time of day, we also note that $\mathrm{P}$ categorizes the appointment herself as 'routine' (line 6). While patients may resist ('just') 'routine' as formulated by receptionists, Extract 8 provides evidence that patients know what this institutional category means and may use it (here, as a resource to avoid any further pursuit of her husband's condition).

In Extracts 9 and 10, we show a different way to solicit an account from patients, which avoids contrasting 'routine' or 'urgent' categories and is less risky than asking an entirely open wh-question as in Extracts 7 and 8.

Extract 9: GP3 120

1 R: Good afternoon, surgery, claire speaking.

2 P: Hiya, =>I was wondering< if you've got any appointments=either

3 .hhh (.) like later on today o:r tomorrow morning,

4 R: $\quad$ Is it something urgent that you're requiri:ng.

$5 \quad(0.3)$

6 P: Uhm I've g- I think I've got a chest infection and I need an

7 inhaler.

$8 \quad \mathrm{R}$ : $\mathrm{N}$ : ot be a second.

P has already indicated 'urgency' in her inquiry, by specifying a requested time (lines 2-3): 'later on today o:r tomorrow morning,'. While R might be required institutionally to initiate triaging, there are also interactional features in P's inquiry to support doing so: $\mathrm{P}$ has explicitly requested a same-day appointment. R asks 'Is it something urgent that you're requiri:ng.' (line 4). Following a gap of 0.3s (line 5), and an 'Uhm' (line 6), P gives details of her condition ('I've got a chest infection') and needs ('I need an inhaler.') in lines 6-7. This is accepted by $\mathrm{R}$ as sufficient reason for a same-day appointment in line 8 , as she indicates a goahead on the appointment booking.

Note that, compared to earlier examples, the patient more straightforwardly supplies an account without resisting the 'urgent' category proposed by R. And compared to the polar interrogatives in some of the earlier examples ('is it just a routine appointment'), which requested confirmation, this time the query takes the form of a polar interrogative not simply requesting confirmation. Specifically, the receptionist's use of 'something' seems to work in favour of soliciting an account rather than just a 'yes'/'no' (dis)confirmation. This supports previous research, which has shown how replacing 'any/anything' with 'some/something' in doctors' questions to patients whether they have additional concerns (i.e., 'Is there (some/any)thing else you would like to address in the visit today?'), significantly increases patients' expression of unanticipated concerns (Heritage et al., 2007). This is because a 'yes' response implies there is an additional concern; and whereas 'any/anything' is negatively polarised and thereby grammatically fitted with a 'no' response, 'some/something' is 
positively polarised and grammatically fitted with a 'yes' response. On this basis we propose that positively polarised features such as 'some(thing)' is well suited at soliciting such an account in questions including 'is it [something] urgent'.

Similarly, in Extract 10, the receptionist solicits the patient's account.

Extract 10: GP3 256

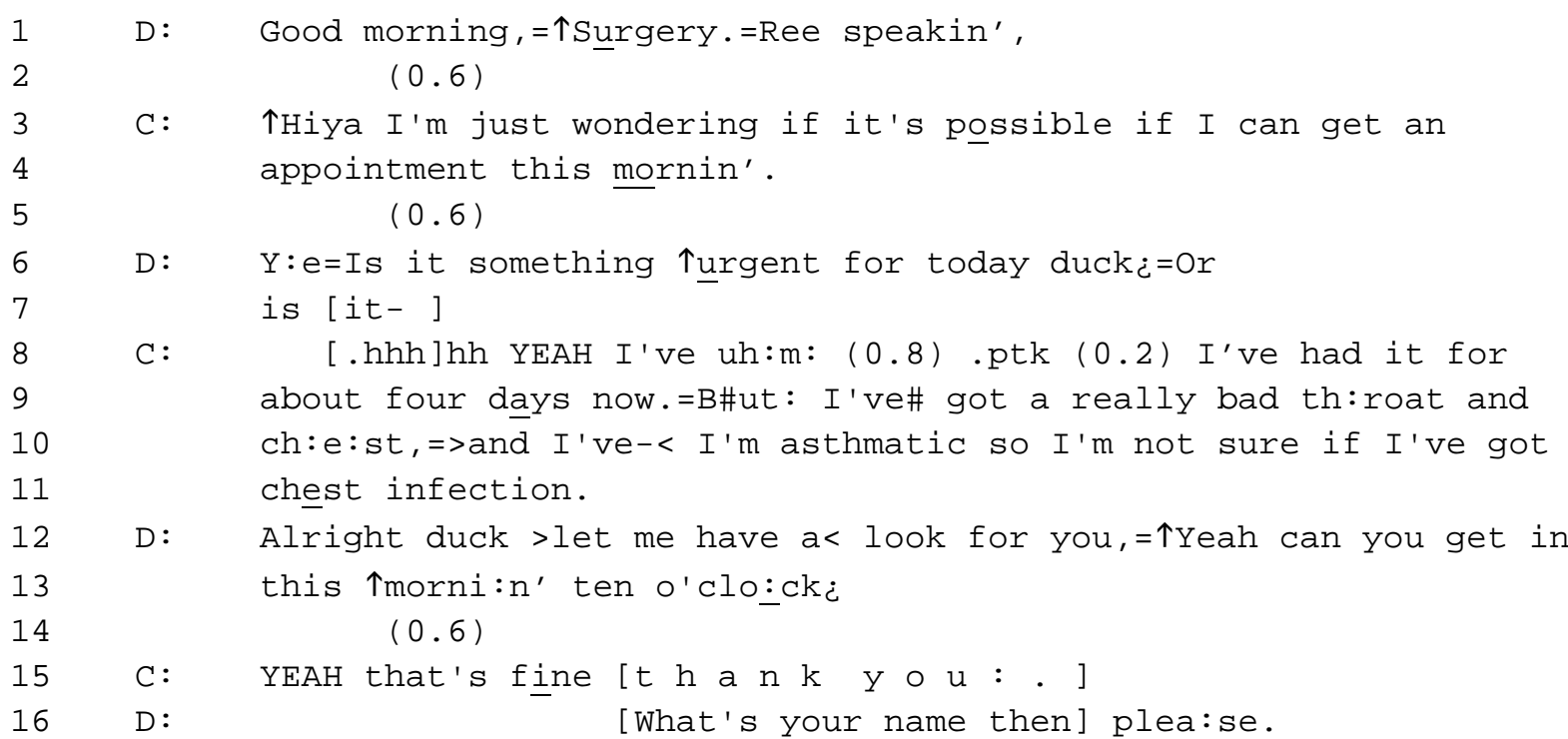

As $\mathrm{R}$ projects a next turn constructional unit with 'Or is it' in lines 6-7, and thus deleting any particular preference to the question in the first part of her turn, P responds to 'Is it something Turgent for today duckéd' in overlap, with an emphatic confirmation 'YEAH' followed by an account: P highlights the duration of the symptoms, and also their severity ('got a really bad th:roat and ch:e:st,').

Extract 11 shows a less emphatic response, with a comparatively downgraded 'He's not $>$ very well $<$ with his stomach.' ( $\mathrm{P}$ is calling on behalf of her partner). This is followed by expanded triaging queries, and eventually the booking of a same-day appointment.

Extract 11: GP3 73, $0: 03-0: 29$

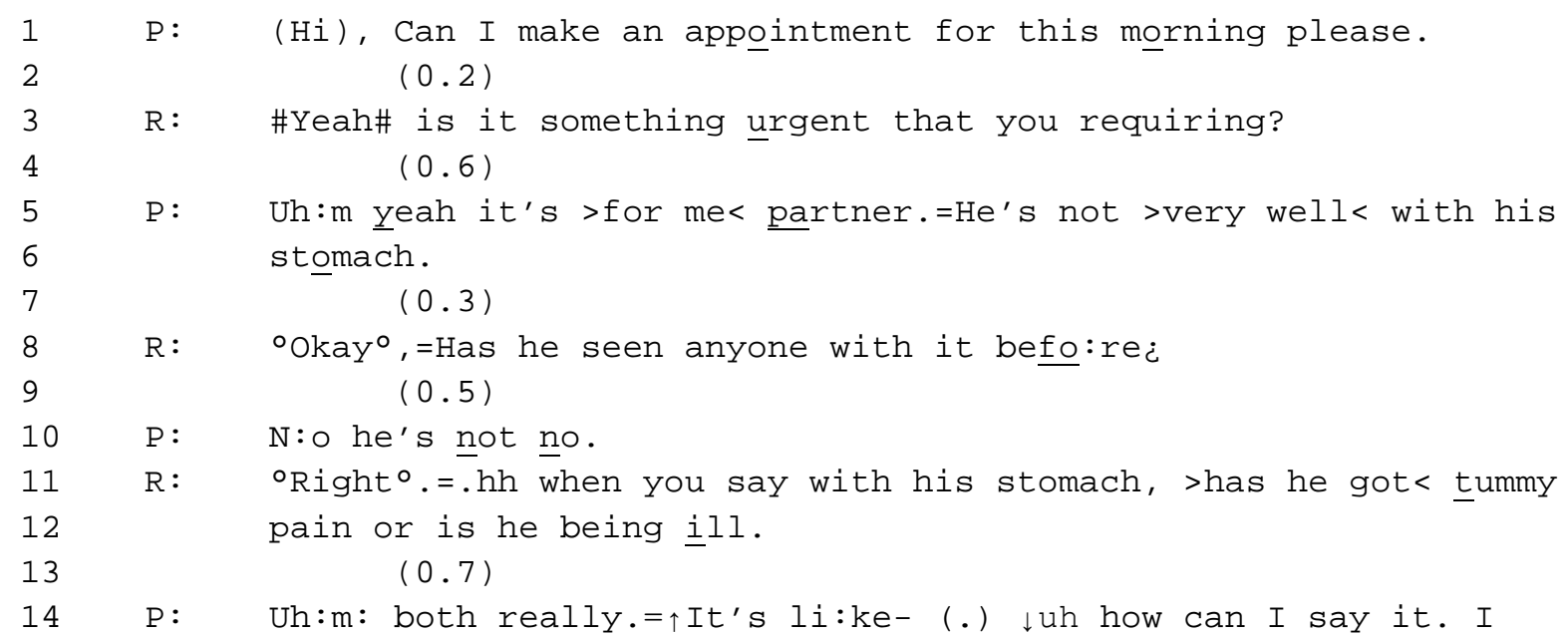




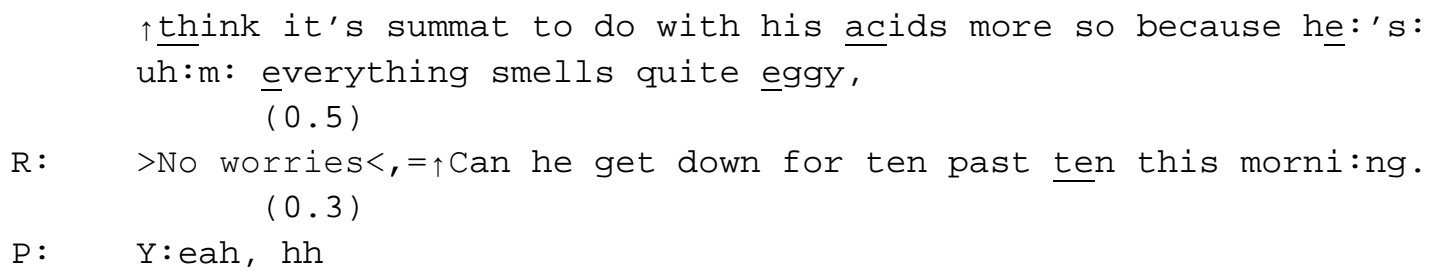

Extract 11 shows that patients' confirmation + accounts are not necessarily treated as evidence of a need for a same-day appointment; in this case the receptionist only offers a same-day appointment once she has gathered some more information about P's husband's condition. In Extract 12 we see that not all patients confirm urgency following 'something urgent for today' - this is treated as dependant on their needs (in this case P wants to renew her prescriptions).

Extract 12: GP2 374

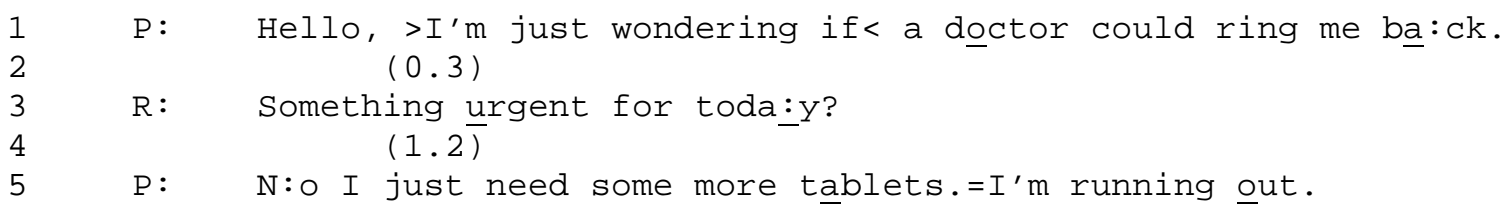

In sum, we have seen that when receptionists use formats such as, 'is it something urgent for today', they may solicit a confirmation plus account from patients, rather than the resistance that follows 'is it just a routine appointment', and when contrasting 'urgent' with 'routine' categories. We have shown how this distinction can have implications for the progressivity of the call. We argued for the role of 'something' in soliciting a further expansion. A key difference between 'is it something urgent for today' and 'is it just a routine appointment' is that the first design orients to and affords patient needs, in other words it assumes patients have a legitimate reason for calling (cf. Murdoch et al., 2014).

\subsection{Flexible triaging: How patients indicate urgency in their first turn}

In the previous sections, we have seen that patients may request to be seen on the same day, prior to or following receptionist-led triaging. In this section, we focus on the patients' first turn pre-triaging, to establish whether and how receptionists may spot urgency based on the patients' formulation of their inquiry. Putting to one side institutional requirements (i.e., the practice policy to initiate triaging), we examine the interactional evidence in support (or not) of triaging, and what makes sense from the patient's perspective.

We will show first that patients may ask for an appointment 'today' in their first turn, in which case asking questions about 'urgency' become legitimate. In other cases, however, there is no such indication of urgency in the patient's first turn. In these cases, patients generally accept a future appointment, especially if that appointment is within the next 3-4 days. Based on our finding that patients themselves make distinctions of urgency available to the GP receptionist in their first turn, we argue that triaging should be used flexibly. Doing triaging by default is not sufficiently attentive to patients. 
In Extract 13, the patient indicates urgency in their first turn; however, the receptionist goes on to treat the inquiry as non-urgent.

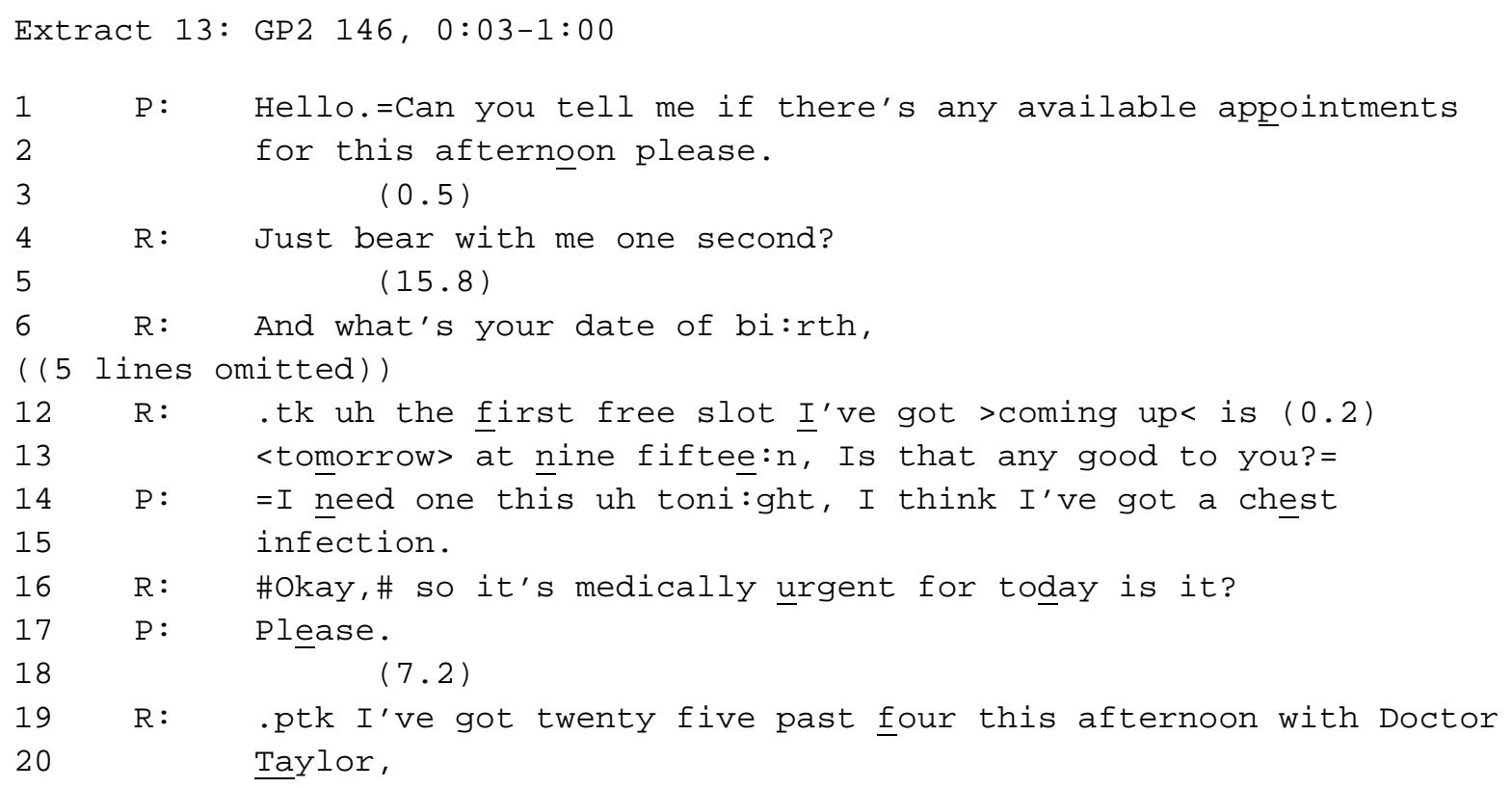

$\mathrm{P}$ requests an appointment for 'this afternoon' in lines 1-2. $\mathrm{R}$ does not initiate triaging in response, but shows that she is looking for availability on the system. $\mathrm{R}$ then offers the 'first free slot' (which is not 'this afternoon') at lines 12-13, and asks P if that is 'any good' (note the negatively polarised 'any', which prefers 'no'). P then upgrades her need for a same-day appointment ('I need one this uh toni:ght') and supplies an account ('I think I've got a chest infection.', lines 14-15). R then formulates the upshot of P's request, which also initiates triaging, with a confirmation request: 'so it's medically urgent for today is it?'.

For comparison, the patient in Extract 14 asks for an appointment without specifying day or urgency.

\section{Extract 14: GP2 314}

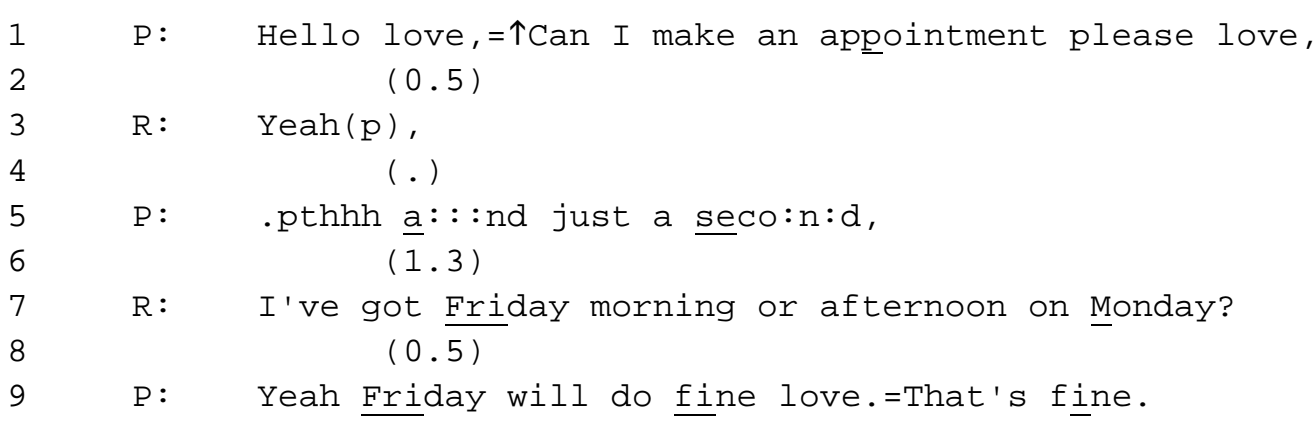

P does not specify time in the initial inquiry, but asks 'Can I make an appointment please love,' (line 1). Arguably, there is little evidence of urgency here, and R goes on to offer the next appointment which is Friday on the same week, or Monday the week after (we do not know what day the patient is calling; however, it seems to be at least two days before 
'Friday'). Thus, if patients do not ask for an immediate appointment, offering the next available one is the appropriate thing for receptionists to do next - there is no need to initiate triaging.

Extract 15 is similar.

Extract 15: GP1 75

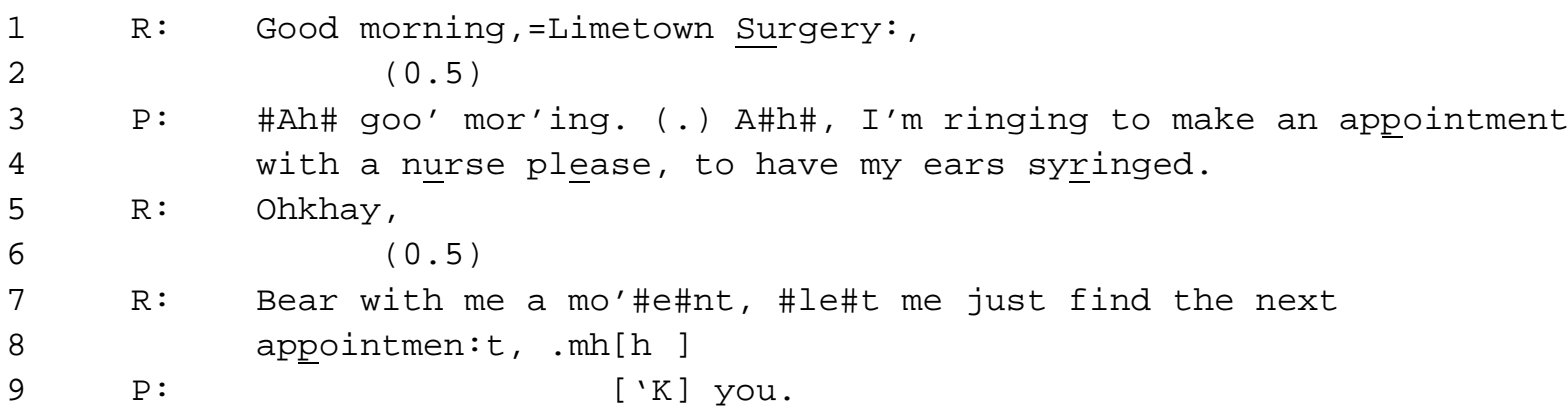

Here, P's request does not specify a time or that she requires this service today, and appears happy with R's offer to 'just find the next appointment' (note her truncated 'thank you' at line 9). Finally, in Extract 16, P designs her request as non-urgent from the start of the call.

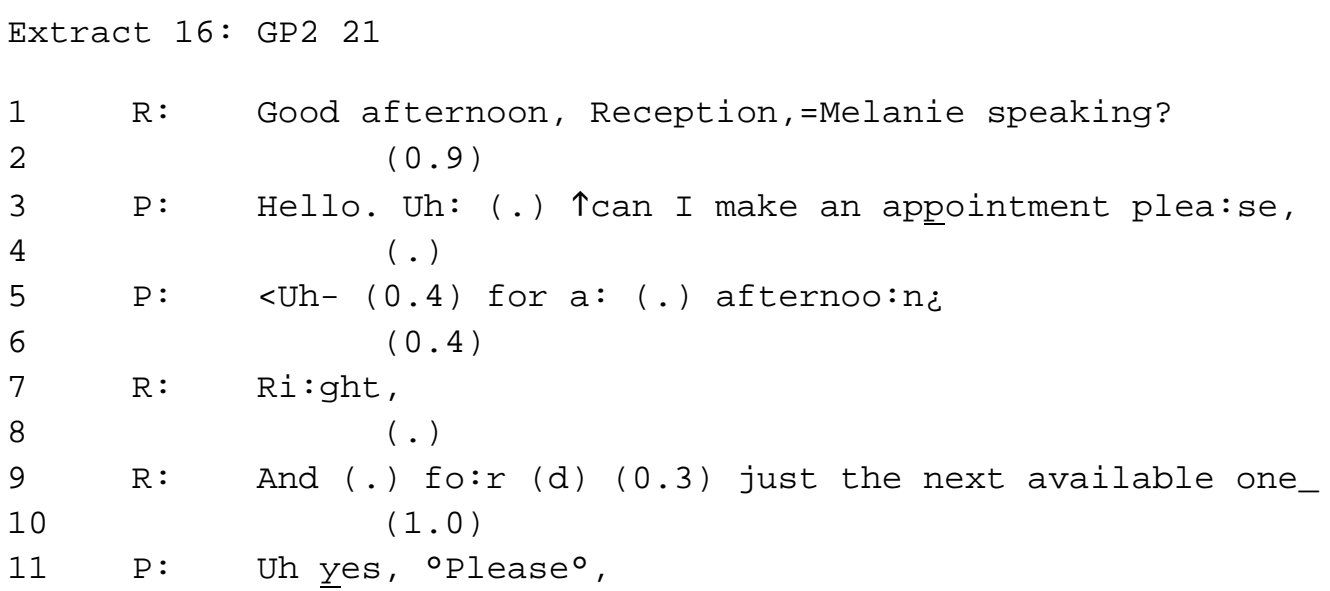

Note that P elaborates the non-urgency of her request for an appointment 'for a: (.) afternoo: $n_{\dot{c}}$ ' (line 5). While she requests that the appointment be at a particular time of day, she does not request that the time of the appointment is soon. We also note that $\mathrm{P}$ confirms 'just the next available one_', which is a very different response to Extracts 1-3, where P is asked to confirm that their appointment is 'just routine'.

Here, then, receptionists make fitted responses to the 'clues' about 'routine' or 'urgent' given by patients. Receptionists may categorise patient requests as 'just routine' - but only after patients have explicitly or implicitly categorized their needs as such. If their needs are urgent, patients indicate this by, for example, requesting an appointment 'today'. 


\section{Implications for healthcare practice}

Without analysing actual calls, how would one know what is effective, or not, when initiating triaging? How does one know what to recommend in terms of receptionists' behaviour, without first knowing what works and what is less effective in their encounters with patients? This study has three key implications: for knowing when to initiate formal triaging at the general practice reception and guiding practice policy; for establishing this insight in the first place; and for training receptionist staff themselves.

Our findings showed that there are different ways - linguistic formats - to ask patients about the routine or urgent status of their appointment requests, and that these linguistic formats vary in how effectively they establish these needs. Our analysis showed that patients resisted categorising their needs either as 'routine' or 'urgent' and were reluctant to confirm that they had a problem that was 'just routine'. Our evidence suggests that patients always regard themselves as calling for a legitimate reason. However, they responded straightforwardly to questions for which confirmation was better fitted to their needs (e.g., 'is it something urgent for today?'), as they opened up a slot to demonstrate legitimacy. Thus, the institutional categories 'routine' and 'urgent' are unhelpful when built into triaging questions from receptionists, and counterproductive when communicating with patients. Given the difficulty in securing appointments, one interpretation is that patients do not describe their needs as 'routine' for fear of positioning themselves explicitly as low priority. But patients may also be reluctant to take a 'genuinely urgent' appointment if their need is somewhere in between. There is moral work at play here.

While there is increasing attention towards patient-centredness (e.g., Bensing, Rimondini and Visser, 2013) and how to reduce pressure on the National Health Service and 'over-use' of Accident and Emergency services in particular, there remains a gap between what we know about receptionists' work, and the (limited) training they receive. We also know that practice staff struggle to identify and action changes based on survey feedback alone (Boiko et al., 2014). Like Hammond et al. (2013), we argue that GP receptionists are well placed to gauge what patients need, as well as knowing the limitations and constraints of their own work, and we cannot understand the work of receptionists without studying it from within their work context. We also argue that the empirical evidence on what needs to change needs to start with actual receptionist-patient encounters, such as this study, showing how some of the challenges regarding triaging arise (see also Hewitt et al., 2009; Sikveland et al., 2016). For example, Sikveland et al. (2016) showed how patients regularly have to 'push' for service at GP receptions at various stages in the encounter (see also Stokoe et al., 2016). If there needs to be such a thing as a protocol for receptionist-led triaging, we first of all need to assess how this works in the real world, in dealing with real patient problems, before attempting to formulate what rules receptionists can break and when. This need for real world focus extends to other healthcare contexts as well, involving different kinds of healthcare professionals (Drew et al., 2001).

Based on the empirical evidence above, we recommend category-avoidance and flexibility when responding to patient inquiries rather than doing formal triaging by default. We recommend receptionists avoid specifying an appointment as 'routine' unless the patient does 
so themselves. In order to recognise when, and how, it is productive to ask whether an inquiry is urgent, we show how patients themselves make such distinctions available to the GP receptionist. Future research might evaluate to what extent receptionists might thereby avoid both over-triaging (i.e., patients who need urgent care do not get it), and under-triaging (i.e., too many patients get a same-day appointment where it is not needed), using these recommendations.

\section{Conclusions}

This chapter follows a growing body of research that demonstrates how evidence endogenous to interactions provides novel insights into how communication works in healthcare contexts, which can then inform training and interventions. It identifies some key indicators of (in)effective patient care, and provides an evidence base from which to develop interventions that are relatively cheap and do not require large-scale organisational changes. The study confirms how each turn in an interaction is interpreted, by the recipient, for its relevance, and that the linguistic and sequential features are consequential for accomplishing understanding, alignment and progressivity. Specifically, we have shown how receptionists can remain focussed on the patient's needs as well as their triaging requirements by formatting their questions in ways that open up for patients to demonstrate, rather than defend, legitimacy.

\section{References}

Arber, S. and Sawyer, L. (1985) 'The role of the receptionist in general practice: A “dragon behind the desk”?', Social science \& medicine, 20(9), pp. 911-921.

Bensing, J., Rimondini, M. and Visser, A. (2013) 'What patients want', Patient education and counseling, 90(3), pp. 287-290.

Boiko, O., Campbell, J. L., Elmore, N., Davey, A. F., Roland, M. and Burt, J. (2014) 'The role of patient experience surveys in quality assurance and improvement: a focus group study in English general practice', Health Expectations, p. 1982.

Bunn, F., Byrne, G. and Kendall, S. (2004) 'Telephone consultation and triage: effects on health care use and patient satisfaction', in Bunn, F. (ed.) Cochrane Database of Systematic Reviews. Chichester, UK: John Wiley \& Sons, Ltd. doi: 10.1002/14651858.CD004180.pub2.

Campbell, J. L., Fletcher, E., Britten, N., Green, C., Holt, T. A., Lattimer, V., Richards, D. A., Richards, S. H., Salisbury, C. and Calitri, R. (2014) 'Telephone triage for management of same-day consultation requests in general practice (the ESTEEM trial): a cluster-randomised controlled trial and cost-consequence analysis', The Lancet, 384(9957), pp. 1859-1868.

Curl, T. S., Local, J. and Walker, G. (2006) 'Repetition and the prosody - pragmatics interface', Journal of Pragmatics, 38, pp. 1721-1751. doi: 10.1016/j.pragma.2006.02.008.

Drew, P. (1997) ““Open” class repair initiators in response to sequential sources of troubles in conversation’, Journal of Pragmatics. North-Holland, 28(1), pp. 69-101. doi: 10.1016/S0378-2166(97)89759-7.

Drew, P., Chatwin, J. and Collins, S. (2001) 'Conversation analysis: a method for research into interactions between patients and health-care professionals’, Health Expectations, 4(1), pp. 58-70.

French, P. and Local, J. (1983) 'Turn-competitive incomings’, Journal of Pragmatics. North-Holland, 7(1), pp. 17-38. doi: 10.1016/0378-2166(83)90147-9.

Gallagher, M., Huddart, T. and Henderson, B. (1998) 'Telephone triage of acute illness by a practice nurse in general practice: outcomes of care.', The British journal of general practice : the journal of the Royal College of General Practitioners. British Journal of General Practice, 48(429), pp. 1141-5. Available at: 
http://www.ncbi.nlm.nih.gov/pubmed/9667088 (Accessed: 4 October 2017).

Gallagher, M., Pearson, P., Drinkwater, C. and Guy, J. (2001) 'Managing patient demand: a qualitative study of appointment making in general practice’, British Journal of General Practice, 51(465), pp. 280-285.

Gillam, S. (2014) 'Telephone triage in-hours: does it work?', The British journal of general practice : the journal of the Royal College of General Practitioners. British Journal of General Practice, 64(624), pp. 327-8. doi: 10.3399/bjgp14X680377.

Hall, S. J., Phillips, C. B., Gray, P., Barnard, A. and Batt, K. (2011) 'Where there is no gold standard: Mixed method research in a cluster randomised trial of a tool for safe prioritising of patients by medical receptionists', International Journal of Multiple Research Approaches. Routledge, 5(1), pp. 25-39. doi: 10.5172/mra.2011.5.1.25.

Hammond, J., Gravenhorst, K., Funnell, E., Beatty, S., Hibbert, D., Lamb, J., Burroughs, H., Kovandzic, M., Gabbay, M., Dowrick, C., Gask, L., Waheed, W. and Chew-Graham, C. A. (2013) 'Slaying the dragon myth: an ethnographic study of receptionists in UK general practice', The British journal of general practice : the journal of the Royal College of General Practitioners, 63(608), pp. e177-84. doi: 10.3399/bjgp13X664225 [doi].

Heritage, J. (2015) 'Well-prefaced turns in English conversation: A conversation analytic perspective', Journal of Pragmatics, 88, pp. 88-104. Available at: https://scholar.google.co.uk/scholar?hl=en\&as_sdt=0\%2C5\&q=well+Heritage+2015\&btnG= (Accessed: 27 October 2017).

Heritage, J. and Raymond, G. (2005) 'The Terms of Agreement: Indexing Epistemic Authority and Subordination in Talk-in-Interaction’, Social Psychology Quarterly, 68(1), pp. 15-38. doi: 10.1177/019027250506800103.

Hesselgreaves, H., Lough, M. and Power, A. (2009) 'The Perceptions of Reception Staff in General Practice About the Factors Influencing Specific Medication Errors', Education for Primary Care. Taylor \& Francis, 20(1), pp. 21-27. doi: 10.1080/14739879.2009.11493758.

Hewitt, H., McCloughan, L. and McKinstry, B. (2009) 'Front desk talk: discourse analysis of receptionistpatient interaction', The British journal of general practice : the journal of the Royal College of General Practitioners, 59(565), pp. e260-6. doi: 10.3399/bjgp09X453774 [doi].

Jefferson, G. (2004) ‘Glossary of transcript symbols with an introduction’, in Lerner, G. H. (ed.).

Amsterdam/Philadelphia: John Benjamins (Conversation analysis: studies from the first generation), pp. 13-31.

Lee, S. H. (2009) 'Extended requesting: Interaction and collaboration in the production and specification of requests’, Journal of Pragmatics, 41(6), pp. 1248-1271. doi: 10.1016/j.pragma.2008.09.013.

Liston, A. (2013) 'GP access - time for a radical solution?’, The British journal of general practice : the journal of the Royal College of General Practitioners, 63(614), p. 483. doi: 10.3399/bjgp13X671687 [doi].

Munro, J., Nicholl, J., O’Cathain, A. and Knowles, E. (2000) 'Impact of NHS direct on demand for immediate care: observational study.', BMJ (Clinical research ed.). British Medical Journal Publishing Group, 321(7254), pp. 150-3. doi: 10.1136/BMJ.321.7254.150.

Murdoch, J., Barnes, R., Pooler, J., Lattimer, V., Fletcher, E. and Campbell, J. L. (2014) 'Question design in nurse-led and GP-led telephone triage for same-day appointment requests: a comparative investigation.', $B M J$ open. British Medical Journal Publishing Group, 4(3), p. e004515. doi: 10.1136/bmjopen-2013-004515.

Neuwelt, P. M., Kearns, R. A. and Cairns, I. R. (2016) 'The care work of general practice receptionists', Journal of Primary Health Care. CSIRO PUBLISHING, 8(2), p. 122. doi: 10.1071/HC15059.

O’Meara, M., Porter, K. and Greaves, I. (2007) ‘Triage’, Trauma. Sage PublicationsSage UK: London, England, 9(2), pp. 111-118. doi: 10.1177/1460408607084180.

Paddison, C. A. M., Abel, G. A., Roland, M. O., Elliott, M. N., Lyratzopoulos, G. and Campbell, J. L. (2013) 'Drivers of overall satisfaction with primary care: evidence from the English General Practice Patient Survey', Health Expectations, p. 1081. 
Patterson, E. A., Forrester, K., Price, K. and Hegney, D. (2005) 'Risk reduction in general practice and the role of the receptionist’, Journal of law and medicine, 12(3), pp. 340-347.

Patterson, E. A., Del Mar, C. and Najman, J. M. (2000) 'Medical receptionists in general practice: Who needs a nurse?', International journal of nursing practice, 6(5), pp. 229-236.

Richards, D. A., Meakins, J., Tawfik, J., Godfrey, L., Dutton, E. and Heywood, P. (2004) 'Quality monitoring of nurse telephone triage: pilot study’, Journal of Advanced Nursing. Blackwell Science Ltd, 47(5), pp. 551-560. doi: 10.1111/j.1365-2648.2004.03132.x.

Robinson, J. D. and Bolden, G. B. (2010) 'Preference organization of sequence-initiating actions: The case of explicit account solicitations’, Discourse Studies. SAGE PublicationsSage UK: London, England, 12(4), pp. 501-533. doi: 10.1177/1461445610371051.

Sacks, H., Schegloff, E. A. and Jefferson, G. (1974) 'A simplest systematics for the organization of turn-taking for conversation', language, pp. 696-735.

Schegloff, E. A. (2007) Sequence organization in interaction. Cambridge: Cambridge University Press.

Sidnell, J. (2016) 'Interactional Trouble and the Ecology of Meaning', Psychology of Language and Communication. De Gruyter Open, 20(2), pp. 98-111. doi: 10.1515/plc-2016-0006.

Sikveland, R. O. (2012) 'Negotiating towards a Next Turn: Phonetic Resources for "Doing the Same”', Language and Speech, 55(1), pp. 77-98. doi: 10.1177/0023830911428859.

Sikveland, R. O. and Zeitlyn, D. (2017) 'Using prosodic cues to identify dialogue acts: methodological challenge’, Text \& Talk. De Gruyter, 37(3), pp. 311-334. doi: 10.1515/text-2017-0007.

Sikveland, R., Stokoe, E. and Symonds, J. (2016) 'Patient burden during appointment-making telephone calls to GP practices', Patient education and counseling.

Speer, S. A. and Stokoe, E. (2014) 'Ethics in action: Consent-gaining interactions and implications for research practice’, British Journal of Social Psychology, 53(1), pp. 54-73.

Stokoe, E., Sikveland, R. O. and Symonds, J. (2016) 'Calling the GP surgery: patient burden, patient satisfaction, and implications for training'.

Swinglehurst, D., Greenhalgh, T., Russell, J. and Myall, M. (2011) 'Receptionist input to quality and safety in repeat prescribing in UK general practice: ethnographic case study’, BMJ : British Medical Journal, 343. doi: 10.1136/bmj.d6788.

\section{Appendix. Transcription Conventions}

The symbols used in this article are adapted from Gail Jefferson's (2004) transcribing conventions.

Symbol Definition

.hh hh Inhalations and exhalations, respectively

Spee::ch Colon indicates a syllable that is drawn out

To- $\quad$ Dash indicates a word has been cut off abruptly

Very Underlining indicates stress or emphasis

(1.4) Numbers in parentheses indicate length of pauses (in seconds) 


\begin{tabular}{|c|c|}
\hline . ¿े? & $\begin{array}{l}\text { Punctuation indicates intonation at the end of units of talk. Full stop } \\
\text { stands for falling intonation, comma for flat intonation, reverse question } \\
\text { mark for slight rise, question mark for sharp rise in intonation. }\end{array}$ \\
\hline [okay] & Square brackets represent overlapping talk \\
\hline$=$ & $\begin{array}{l}\text { End of one turn and beginning of next begin with no gap/pause in } \\
\text { between (usually a slight overlap if there is speaker change) }\end{array}$ \\
\hline (words) & A guess at what might have been said if unclear \\
\hline wo(h)rds & Within-speech breath-bursts (laughter) \\
\hline WORD & Talk produced loudly in comparison with surrounding talk \\
\hline \#word\# & Creaky voice \\
\hline${ }^{\circ}$ word ${ }^{\circ}$ & Quiet, breathy, voice \\
\hline 个word & Marked shift upwards in pitch \\
\hline$\downarrow_{\text {word }}$ & Marked shift down in pitch \\
\hline
\end{tabular}

